\title{
Understanding primary care-oncology relationships within a changing healthcare environment
}

\author{
Jennifer Tsui ${ }^{1 *}$ D, Jenna Howard ${ }^{2}$, Denalee O'Malley², William L. Miller ${ }^{3}$, Shawna V. Hudson ${ }^{1,2}$, Ellen B. Rubinstein ${ }^{4}$,
} Jeanne M. Ferrante ${ }^{2}$, Alicja Bator ${ }^{2}$ and Benjamin F. Crabtree ${ }^{1,2}$

\begin{abstract}
Background: Management of care transitions from primary care into and out of oncology is critical for optimal care of cancer patients and cancer survivors. There is limited understanding of existing primary care-oncology relationships within the context of the changing health care environment.

Methods: Through a comparative case study of 14 innovative primary care practices throughout the United States (U.S.), we examined relationships between primary care and oncology settings to identify attributes contributing to strengthened relationships in diverse settings. Field researchers observed practices for 10-12 days, recording fieldnotes and conducting interviews. We created a reduced dataset of all text related to primary care-oncology relationships, and collaboratively identified patterns to characterize these relationships through an inductive "immersion/crystallization" analysis process.

Results: Nine of the 14 practices discussed having either formal or informal primary care-oncology relationships. Nearly all formal primary care-oncology relationships were embedded within healthcare systems. The majority of private, independent practices had more informal relationships between individual primary care physicians and specific oncologists. Practices with formal relationships noted health system infrastructure that facilitates transfer of patient information and timely referrals. Practices with informal relationships described shared commitment, trust, and rapport with specific oncologists. Regardless of relationship type, challenges reported by primary care settings included lack of clarity about roles and responsibilities during cancer treatment and beyond.

Conclusions: With the rapid transformation of U.S. healthcare towards system ownership of primary care practices, efforts are needed to integrate strengths of informal primary care-oncology relationships in addition to formal system driven relationships.
\end{abstract}

Keywords: Cancer care/oncology, Primary care, Chronic disease management, Healthcare delivery, Physician relationships

\section{Background}

It is estimated that 1.7 million new cancer cases were diagnosed in 2018, and the number of cancer survivors in the United States will reach over 18 million by 2020 $[1,2]$. High quality care from cancer diagnosis through survivorship requires care delivery processes involving different sets of providers and care teams [3, 4]. Poor

\footnotetext{
* Correspondence: jk1341@cinj.rutgers.edu

${ }^{1}$ Division of Population Science, Rutgers Cancer Institute of New Jersey,

Rutgers, the State University of New Jersey, 195 Little Albany, New Brunswick, NJ 08903, USA

Full list of author information is available at the end of the article
}

transitions from primary care to oncology following cancer diagnosis are associated with worse outcomes and lower survival $[3,5,6]$. Suboptimal care coordination - including information transfer and role negotiation among multiple clinicians - during survivorship also remains the norm [7,8]. Shared-care or team-based care, where clinicians interact more interdependently and adaptively to achieve common goals, provide more comprehensive and guideline concordant-care for cancer survivors than when followed by oncology teams only $[9,10]$. Yet, the mechanisms that impact relationship and team building between primary care and oncology

(C) The Author(s). 2019 Open Access This article is distributed under the terms of the Creative Commons Attribution 4.0 International License (http://creativecommons.org/licenses/by/4.0/), which permits unrestricted use, distribution, and 
settings are poorly understood and remain underexplored in health services research $[6,7,11-14]$.

Over the last decade, there has been rapid health care delivery consolidation in the U.S., including the acquisition of independent physician practices into hospital and other integrated systems and payment models [15-17], which can have profound effects in primary care delivery, and management for cancer patients [18-20]. Similarly, shifts from independent oncology practices to larger system affiliations has led to new referral patterns and underlying infrastructure that can affect relationships between primary care and oncology settings [21, 22]. An understanding of existing primary care-oncology relationships within the context of dynamic health care reorganization, including both system-based and independently-owned primary care practices, is necessary to inform long-term strategies for managing the care of cancer patients and survivors.

In this analysis, we describe existing relationships between primary care and oncology settings and identify attributes contributing to strengthened primary careoncology interfaces in diverse settings.

\section{Methods}

\section{Study Sample \& Design}

This a secondary data analysis of qualitative data collected from 2015 to 2017 as part of a National Cancer Institute-funded mixed methods comparative case study of 14 innovative primary care practices throughout the U.S. The parent study was designed to examine attributes of these innovators and their strategies to deliver care for cancer survivors. Practice recruitment and data collection methods were described in detail in previous publications [23, 24]. Briefly, practices were selected from a national list of 151 workforce innovators compiled for the Robert Wood Johnson Foundation in 2011-2012. Most were National Committee for Quality Assurance (NCQA) level 3 Patient-Centered Medical Home practices, diverse in size, geographic location, and ownership. Trained researchers visited each practice for 10-12 business days and collected: (a) observational fieldnotes and key informant interviews on clinical workflow; (b) fieldnotes of "patient pathways" (shadowing cancer survivors through their visit); (c) 54 recorded and transcribed semistructured interviews with clinicians and staff; and, (d) practice documents, such as standard operating procedures, patient educational materials and organizational mission statements. A Practice Information Form on practice characteristics (e.g., size, organization, patient population, services, payment structure, etc.) was completed by a practice leader. The Rutgers University Biomedical and Health Sciences Institutional Review Board approved the study and written informed consent was obtained from recorded interview participants.

\section{Research questions}

We conducted a comparative case study analysis using data from the parent study to answer the following questions (1]: What are the key features of primary care and oncology relationships across health care settings, specifically regarding patients' transitions into and out of acute cancer treatment? and (2) Which attributes of these relationships can be adapted to strengthen the quality of care transitions for cancer patients in other settings?

\section{Data analysis}

The compiled dataset from the parent study, consisting of over 2000 pages of qualitative data, was managed and coded using Atlas.ti software (Version 7.5.3). Initially, we applied a data reduction strategy from the 2000 pages of qualitative data and extracted all text on the topic of relationships between primary care and oncology providers using the following key terms: "oncology"/"oncologist," "cancer center," "referral," "cancer diagnosis," and "cancer treatment." Data were analyzed using a grounded theory inductive approach [25], which involves a series of iterative and interpretive immersion/ crystallization cycles of reading and analyzing the data until patterns and themes emerge [26]. Two authors (JT and $\mathrm{JH}$ ) independently read the reduced dataset to identify patterns. This second reading clarified which primary care clinicians at which practices spoke about their interactions with oncology. The two authors then wrote short case summaries that described each practice's relationship with oncology and shared these with the larger research team, including the field researchers who collected the data, to reflect together on themes. We compared and contrasted each practice with our emergent themes and engaged in several iterative rounds of rereading the data and collaboratively reflecting before agreeing on the final characterization of primary careoncology relationships. Quantitative information on practice characteristics from the Practice Information Forms was examined and compiled into Table 1.

\section{Results}

The 14 practices were located in diverse settings (four urban, two in small cities, six suburban, two rural) across nine states (See Table 1). They represented various practice types, including five physician-owned (2 being Direct Primary Care models), three hospital or health system-owned, one Veteran's Administration (VA) practice, one university nurse-led, one capitated non-profit, one practice within a network of independent primary care practices, and two Federally Qualified Health Centers (FQHCs). Other analyses of these 14 practices explored primary care physicians' perspectives on cancer survivorship care [27] and barriers and opportunities for 
Table 1 Primary care practice charactristics by formal and informal primary care-oncology relationship

\begin{tabular}{|c|c|c|c|c|c|c|c|}
\hline Practice ID & Location & Ownership & $\begin{array}{l}\text { \# of Primary Care } \\
\text { Physicians }\end{array}$ & $\begin{array}{l}\text { \# of NPs } \\
\text { or PAs }\end{array}$ & $\begin{array}{l}\text { \# of Patient } \\
\text { Visits per Year }\end{array}$ & $\begin{array}{l}\text { \% Medicaid or } \\
\text { Uninsured Patients }\end{array}$ & $\begin{array}{l}\text { \% Minority } \\
\text { Patients }\end{array}$ \\
\hline \multicolumn{8}{|c|}{ Formal Primary Care-Oncology Relationship } \\
\hline P6 & Rural & FQHC within Health System & 8 & 8 & 33,233 & 19 & 4 \\
\hline P9 & Urban & Capitated Non-Profit, Independent Practice & 11 & 2 & 44,000 & 5 & 79 \\
\hline P10 & Suburban & Academic- Hospital Health System & 12 & 3 & 26,000 & 8 & 64 \\
\hline P11 & Suburban & Veterans Administration & 5 & 0 & 9151 & 0 & unk \\
\hline \multicolumn{8}{|c|}{ Informal Primary Care-Oncology Relationship } \\
\hline P1 & Suburban & Independent, Physician Owned & 10 & 3 & 84,000 & 9 & 5 \\
\hline P2 & Suburban & Independent, Physician Owned & 6 & 2 & 19,933 & 10 & 10 \\
\hline P4 & Rural & $\mathrm{FQHC}$ & 7 & 2 & 25,000 & unk & unk \\
\hline P8 & Suburban & Independent, Physician Owned & 3 & 3 & 19,380 & 1 & 21 \\
\hline P14 & Small city & Independent, Physician Owned & 3 & 2 & 4771 & 60 & 7 \\
\hline \multicolumn{8}{|c|}{ No Relationship Mentioned } \\
\hline P3 & Suburban & Hospital Health System & 7 & 4 & 37,828 & 8 & 6 \\
\hline P5 & Suburban & Health System & 3 & 1 & 9447 & 6 & unk \\
\hline P7 & Urban & University Nurse-Led, FQHC & 1 & 4 & 11,035 & 87 & 71 \\
\hline P12 & Urban & Private, direct primary care & 5 & 1 & 9557 & 32 & unk \\
\hline P13 & Suburban & $\begin{array}{l}\text { Private practice within network of independent } \\
\text { practices }\end{array}$ & 3 & 0 & 5791 & 0 & unk \\
\hline
\end{tabular}

FQHC Federally Qualified Health Center, unk Unknown/Missing

systematic cancer survivorship care in advanced primary care practices [24]. These prior analyses revealed a limited primary care identity within the broader healthcare context for cancer survivorship care and lack of ability of current information systems to support survivorship care. While these findings are relevant to the relationship between primary care and oncology, this analysis focuses explicitly, and with more depth, on understanding these practice's specific relationships with oncologists.

Nine of the 14 practices (i.e. P1, P2, P4, P6, P8, P9, $\mathrm{P} 10, \mathrm{P} 11, \mathrm{P} 14)$ discussed features of existing relationships with oncologists. Of these, four described formal relationships between their practice and oncologists or hospital oncology services (P6, P9, P10, P11). Formal relationships included either being within the same hospital-owned health system or having a financial contract with specific oncologists. Five practices, which were not based within hospital or health system-owned settings, spoke about relationships with oncology that relied more on personal relationships between individual physicians and oncologists (P1, P2, P4, P8, P14). We provide examples below to characterize the two types - formal versus informal relationships - and the impact of these relationships on cancer care transitions.

\section{Formal primary care-oncology relationships}

The primary care practices with formal relationships with oncology settings, included an $\mathrm{FQHC}$ within a rural health system (P6), a hospital-owned academic residency
(P10), a Veterans Administration (VA) communitybased outpatient clinic (CBOC) (P11), and an independent, non-profit primary care practice that employed its own part-time specialists, including multiple oncologists (P9). Three case studies (two system-based; one independent), described below, characterize these formal primary care-oncology relationships.

\section{CASE \#1: FQHC within rural system}

P6 is a large FQHC within a 17-clinic health system that refers most cancer cases to the local hospital's cancer center. The health system established a memorandum of understanding (MOU) between the primary care clinics and the hospital's oncology department, with the purpose of improving communication around mutual patients' care during cancer treatment and "to reduce duplicative services between primary and oncology care" after treatment, as described by one primary care physician. Another physician identified some of the problematic issues that had motivated creating a formalized process between these care settings:

Our MOU with oncologists really is trying to find the right relationship between primary care and the oncologists, and we are frustrated by two sets of things happening. One is the patients who really are failing on aggressive care continue to get it when they don't need it and not being offered the palliative services. And then the other frustration is 
people 10 years out being called back every 4 months for more [tests] ...

Reported benefits of having this formalized agreement included a reliable process of receiving oncology notes, a registry of shared patients, and consistent referral patterns, allowing for timely access to oncologists.

\section{CASE \#2: hospital-owned academic residency clinic}

Another example of a formal structured primary careoncology relationship is P10, a large, urban hospital-owned academic residency clinic with an academic affiliation to a National Cancer Institute (NCI)-designated comprehensive cancer center, located a mile away. Nearly all oncology referrals are sent to the cancer center, which was spoken of highly by several physicians and staff.

Clinicians in P10 also mentioned that having a shared electronic health record (EHR) and email system has contributed to the positive relationship:

[I] think it's a really great working relationship, but I mean I think the nice thing is that we're connected by the Epic [EHR] system and email. We can see their visits. We can message them through the system. Patients get referred by the hospital or from here ... I think it's a really great relationship.

The referral of patients was in fact a reciprocal process between P10 and the cancer center. It was common for the cancer center to ask the practice to assign P10 clinicians for new patients seeking care at the center who did not currently have an affiliated primary care clinician.

\section{CASE \#3: independent, non-profit clinic}

While it was generally the case that structured primary care-oncology relationships occurred within systembased practices, P9 was the exception. P9 developed formal relationships with oncologists by hiring several onsite specialists, including two oncologists and a surgeon. Exchange of health information, electronically and verbally, was seamless both because primary care clinicians and in-house specialists used the same EHR and because they saw patients within the same clinic. The P9 surgeon explained: "[The typical] black box [between oncology and primary care] is better here because we can have ongoing communication." A P9 oncologist highlighted that one of the advantages of having oncologists and primary care providers working together in the same practice is that patients get into treatment quickly after a diagnosis. One P9 oncologist was also employed by a large, academic hospital/cancer center, which added to the ease in communication between the primary care providers and external oncologists involved in patient care.

\section{Informal primary care-oncology relationships}

There were five practices (P2, P4, P8, P1, P14) that did not have any kind of structured relationships with oncology, yet clinicians in these practices described having informal relationships with individual oncologists. All five were private, independent practices that had no health system-affiliation. The context that contributed to these clinicians' relationships with oncologists varied across the five practices, but focused mainly on rapport-building and increased efforts for team-based approaches to care. Two case studies below characterize these informal primary care-oncology relationships:

\section{CASE \#1: large, suburban, independent physician-owned practice}

P1 is a large, privately-owned multi-specialty clinic with family- and internal medicine physicians as well as multiple specialists, most of whom sublease space from P1. Although it is located in close proximity to a cancer center, P1 physicians tended not to refer there. They felt the cancer center did not provide good care, so as one physician put it, she "voted with [her] feet long ago" and found, through trial and error, community oncologists who lived up to her expectations:

[T] hey're communicating with me ... they treat my patients with kindness, they're happy to hear from me on the phone, and they're sending me their thoughts ... so it's a whole team approach.

While P1 has the option of multiple oncology groups to refer to within the region, including the local cancer center, they chose to rely on oncologists with whom they felt they could have reciprocal communication and shared care of their patients.

\section{CASE \#2: medium, suburban, independent physician- owned practice}

P2 is a medium-sized, privately owned family medicine practice that has been in existence for 35 years. They have prided themselves in long-term patient relationships, often caring for multiple generations of entire families. Physicians at P2 have prioritized developing "good rapport" with specialists (including oncologists) and therefore decided to round at the hospital rather than using hospitalists. While most primary care physicians in the area have stopped rounding (i.e. when a physician sees patients in the hospital, sometimes with medical trainees, and discuss the overall course of treatment with other members of the health care team, including nurses and specialists) unless they have teaching obligations, P2 physicians chose to continue hospital rounding as a way to cultivate relationships with inpatient care providers. They were willing to invest in 
these relationships because, as the office manager explained, the P2 physicians "want to keep themselves in the loop [of their patients' care]." Even though they are not owned by the hospital, physicians felt strongly that rounding was advantageous:

Being affiliated and knowing the doctors [at the hospital], being able to actually interact with them in front of the patients, knowing that you're all involved in the care is great for them (patients).

Overall, despite their independence as a private practice, P2 developed ways to foster relationships and enhance communication with hospital oncologists.

\section{Discussion}

This is one of few studies to examine characteristics of relationships between primary care and oncology settings within the recent healthcare environment. We found that primary care-oncology relationships situated within formal settings, indicated several common advantages, including having shared health information technology infrastructure, which allowed for rapid and secure patient information transfer between settings, as cited in prior studies [13, 28]. Additionally, shared information systems allowed primary care practices to stay connected to their patients during acute cancer treatment, and facilitated bidirectional referrals. Many characteristics of these relationships may be applicable and already in place between primary care and other specialists (e.g. cardiologists, endocrinologists) for co-managing conditions such as diabetes and hypertension. However, less is understood about the communication systems between primary care and oncology, particularly outside of vertically integrated health systems.

While formal primary care-oncology relationships benefited from the broader health system infrastructure, informal relationships had the advantage of increased rapport between providers in primary care and oncology settings. Although these personal primary care-oncology relationships were often tied to one individual within the organization and thus may not be sustainable long-term, they had the advantages of shared familiarity, trust, and commitment, characteristics that have been noted in other team-based care studies [29-31]. Given that rapid changes in primary care ownership across the U.S. are ongoing, it is important for health systems to encourage team-building between primary care and oncology settings, in addition to strengthening infrastructure for information transfer. Prior studies on relationships between providers, particularly within the context of telemedicine, have supported the need to establish interdependent relationships for optimal teambased care [32-35]. Insight from these case studies contributes to our growing understanding of features of both formal and informal relationships that are important for optimal management of a patient's journey through the cancer care continuum.

Despite the advantages highlighted in either formal or informal relationships with oncologists, clinicians in all practices identified remaining care coordination challenges during acute and survivorship phases of cancer care [14]. For example, multiple primary care clinicians mentioned having limited participation in their patients' care once they transitioned to oncology. There was a lack of clarity in the respective roles and responsibilities of primary care and oncology during care transition points. Lastly, several clinicians in both formal and informal settings mentioned a lack of guidance on appropriate follow-up care plans for survivors. National guidelines on cancer survivorship care indicate that long-term systematic care should take place within primary care settings as the number of cancer survivors continues to increase [36-39]. However, recent studies have shown implementation of systematic survivorship care is extremely limited within primary care practices [24, 40-42]. Substantial efforts to manage the care of cancer survivors systematically within primary care settings and to address barriers to this implementation are warranted [10, 43].

While this is one of few studies using empirical qualitative data to understand relationships between primary care and oncology, it is not without limitations. First, the focus on practice-level relationships rather than clinician relationships may have resulted in missing data on some individual primary care clinicians' relationships with oncologists. This may explain why data from five practices did not reveal any stated primary care-oncology relationships. Furthermore, we did not collect data from oncology practices and were therefore unable to compare perspectives and institutional contexts between the two settings. Although best attempts were made to identify the most relevant individuals to interview regarding cancer care transitions, it is possible that some key informants were not available. Additionally, while our sample of innovative practices was diverse, it was not inclusive of all types of primary care settings. For example, we did not include a primary care practice that is part of a fully integrated health system, such as Kaiser Permanente. These systems may facilitate different relationships between primary and oncology care. Lastly, this study did not include measures of health care quality or outcomes at the patient-level and thus is limited in assessing how variations in primary care and oncology relationships impact clinical endpoints. These limitations notwithstanding, the current study provides important new data on interfaces and relationships between primary care and oncology that affects cancer care management.

\section{Conclusions}

Improvements in the management of care transitions from primary care into and out of oncology are critical 
for achieving optimal care quality and outcomes for cancer patients and survivors. Advantages of strong relationships between generalists and specialists, in general, have been observed in studies as far back as Rhee and colleagues in 1980 [44] and as recently as National Cancer Institute-American Society of Clinical Oncology Teams in Cancer Care Project, specifically for teambased cancer care delivery [4]. While evidence is limited on the relative benefit of formal versus informal primary care-oncology relationships, the increasing number of system/hospital-owned practices may provide additional infrastructure to facilitate such relationships. Findings from this study provide evidence to monitor and further explore the impact of increasing integration of primary care and oncology practices with hospital settings and whether these trends improve communication strategies via more organized infrastructure over time. Furthermore, as the implementation of patient navigators continues to grow in diverse ways, including use of nurses, medical assistants, and community health workers [45-48], it is not yet clear whether any one of these strategies improve primary care and oncology relationships for the care of cancer survivors. As more practices are consolidated into health systems or bound to contractual relationships with specific oncology groups, fostering rapport and team-building among clinicians in these settings may be crucial for optimizing the potential of system-based supports $[49,50]$. Increased research to understand health organizational differences that are associated with team rapport and quality and outcomes for cancer patients are needed [14, 51]. For example, building empirical evidence of the impact of fostering rapport and team building between primary care and oncologists in both formal and informal relationships will contribute to a much needed understanding of how care delivery teams can improve cancer outcomes [52]. Recent studies in building multidisciplinary care teams for cancer patients, through increased team meetings, have improved quality but not survival, suggesting more research is needed in this area [53]. In summary, these study findings provide support to build evidence for strategies to better integrate strengths of informal primary care-oncology relationships in addition to formal system driven relationships that are ongoing within the health care context.

\section{Abbreviations \\ CBOC: Community Based Outpatient Clinic; EHR: Electronic Health Record; FQHC: Federally Qualified Health Center; MOU: Memorandum of Understanding; NCQA: National Committee for Quality Assurance; VA: Veterans Administration}

\section{Authors' contributions}

JT conceived of this secondary analysis, collected, analyzed and interpreted study data, and drafted and revised the manuscript. JH analyzed and interpreted data and contributed to drafting and revising the manuscript. DO contributed to interpreting the data, drafting and revising the manuscript. WLM analyzed and interpreted the data, and contributed writing revisions. SH helped to design the parent study, analyzed and interpreted the data, and suggested revisions to the manuscript. EBR collected, analyzed and interpreted study data, and contributed revisions to the manuscript. JMF contributed substantial revisions to the manuscript. $A B$ contributed to analyzing the data and reviewing the manuscript. BFC conceived of and designed the parent study, analyzed and interpreted data, and significantly revised the manuscript. All authors read and approved the final manuscript.

\section{Funding}

This work was supported by the NCI R01CA176545 grant: "PCMH Implementation Strategies: Implications for Cancer Survivor Care" (PI: Crabtree). J.T.'s effort on this study was supported in part by an American Cancer Society Mentored Research Scholar Grant (17-099-01-CPHPS). The funding bodies did not have any roles in the design of the study and collection, analysis, and interpretation of data and in writing the manuscript.

\section{Availability of data and materials}

The dataset generated and analyzed during the current study is not publicly available because the detailed nature of this qualitative data could compromise participant anonymity.

\section{Ethics approval and consent to participate}

The Rutgers University Biomedical and Health Sciences Institutional Review Board approved the study (IRB Protocol No.: 2013003629) and written informed consent was obtained from recorded interview participants.

\section{Consent for publication}

Not Applicable. All identifying information has been appropriately anonymized and there are no identifying images used within the manuscript.

\section{Competing interests}

The authors declare they have no competing interests.

\section{Author details}

${ }^{1}$ Division of Population Science, Rutgers Cancer Institute of New Jersey, Rutgers, the State University of New Jersey, 195 Little Albany, New Brunswick, NJ 08903, USA. Department of Family Medicine and Community Health, Rutgers Robert Wood Johnson Medical School, Rutgers, the State University of New Jersey, 112 Paterson St, New Brunswick, NJ 08901, USA. ² Lehigh Valley Health Network, University of South Florida Morsani College of Medicine, 1247 S. Cedar Crest Blvd., Allentown, PA 18103, USA. ${ }^{4}$ Department of Sociology and Anthropology, North Dakota State University, 428 Minard Hall, 1210 Albrecht Boulevard, Fargo, ND, USA.

Received: 28 March 2019 Accepted: 21 November 2019

Published online: 28 November 2019

\section{References}

1. American Cancer Society. Cancer Treatment \& Survivorship Facts \& figures 2016-2017. Atlanta: American Cancer Society; 2016.

2. American Cancer Society. Cancer Facts \& Figures 2018. Atlanta: American Cancer Society; 2018. https://www.cancer.org/content/dam/cancer-org/ research/cancer-facts-and-statistics/annual-cancer-facts-and-figures/2018/ cancer-facts-and-figures-2018.pdf.

3. Taplin SH, Rodgers AB. Toward improving the quality of cancer care: addressing the interfaces of primary and oncology-related subspecialty care. J Natl Cancer Inst Monogr. 2010;2010(40):3-10.

4. Kosty MP, Hanley A, Chollette V, Bruinooge SS, Taplin SH. National Cancer Institute-American Society of Clinical Oncology teams in cancer care project. J Oncol Pract. 2016;12(11):955-8.

5. Anhang Price R, Zapka J, Edwards H, Taplin SH. Organizational factors and the cancer screening process. J Natl Cancer Inst Monogr. 2010;2010(40):38-57.

6. Taplin SH, Clauser S, Rodgers AB, Breslau E, Rayson D. Interfaces across the cancer continuum offer opportunities to improve the process of care. J Natl Cancer Inst Monogr. 2010;2010(40):104-10.

7. Grunfeld E, Earle CC. The interface between primary and oncology specialty care: treatment through survivorship. J Natl Cancer Inst Monogr. 2010; 2010(40):25-30.

8. Guassora AD, Jarlbaek $L$, Thorsen T. Preparing general practitioners to receive cancer patients following treatment in secondary care: a qualitative study. BMC Health Serv Res. 2015;15:202. 
9. Snyder CF, Earle CC, Herbert RJ, Neville BA, Blackford AL, Frick KD. Trends in follow-up and preventive care for colorectal cancer survivors. J Gen Intern Med. 2008;23(3):254-9.

10. Tremblay D, Latreille J, Bilodeau K, Samson A, Roy L, L'Italien MF, et al. Improving the transition from oncology to primary care teams: a case for shared leadership. J Oncol Pract. 2016;12(11):1012-9.

11. Nekhlyudov L, Latosinsky S. The interface of primary and oncology specialty care: from symptoms to diagnosis. J Natl Cancer Inst Monogr. 2010; 2010(40):11-7.

12. Prouty CD, Mazor KM, Greene $\mathrm{SM}$, Roblin DW, Firneno CL, Lemay CA, et al. Providers' perceptions of communication breakdowns in cancer care. J Gen Intern Med. 2014;29(8):1122-30.

13. Sada $Y H$, Street RL Jr, Singh $H$, Shada RE, Naik AD. Primary care and communication in shared cancer care: a qualitative study. Am J Manag Care. 2011;17(4):259-65.

14. Weaver SJ, Jacobsen PB. Cancer care coordination: opportunities for healthcare delivery research. Transl Behav Med. 2018;8(3):503-8.

15. Andrulis DP, Siddiqui NJ, Swapna Reddy J, Jahnke LR, Cooper MMR. Safetynet hospital systems transformation in the era of health care reform: Texas Health Institute. Online at http://www.texashealthinstituteorg/ uploads/1/3/5/3/13535548/safetynet_systems_transformation_in_era_of _reform___full_report.pdf; 2015.

16. Isaacs SL, Jellinek PS, Ray WL. The independent physician--going, going. N Engl J Med. 2009;360(7):655-7.

17. Peterson LE, Baxley E, Jaen CR, Phillips RL. Fewer family physicians are in solo practices. J Am Board Fam Med. 2015;28(1):11-2.

18. Carlin CS, Feldman R, Dowd B. The impact of Hospital Acquisition of Physician Practices on referral patterns. Health Econ. 2016;25(4):439-54.

19. Christianson JB, Carlin CS, Warrick LH. The dynamics of community health care consolidation: acquisition of physician practices. Milbank Q. 2014;92(3): 542-67

20. Essary AC, Green EP, Gans DN. Compensation and production in family medicine by practice ownership. Health Serv Res Manag Epidemiol. 2016;3: 2333392815624111.

21. Bach PB. Limits on Medicare's ability to control rising spending on cancer drugsMass Medical Soc; 2009.

22. Conti RM. Expanding the scope of the National Practice Oncology Benchmark Would be a critical source for understanding outpatient oncology practice costs and profits in a time of change. J Oncol Pract. 2015; 11(1):e95-e7.

23. Tsui J, Hudson SV, Rubinstein EB, Howard J, Hicks E, Kieber-Emmons A, et al. A mixed-methods analysis of the capacity of the patient-centered medical home to implement care coordination services for cancer survivors. Transl Behav Med. 2018;8(3):319-27.

24. Rubinstein EB, Miller WL, Hudson SV, Howard J, O'Malley D, Tsui J, et al. Cancer survivorship Care in Advanced Primary Care Practices: a qualitative study of challenges and opportunities. JAMA Intern Med. 2017;177(12): 1726-32.

25. Corbin J, A. S. Grounded theory Reearch: procedures, canons, and evaluative criteria. Grounded Theory Res. 1990;13:3-21.

26. Crabtree BF, Miller WL. Doing quality research in primary care: multiple strategies. 2nd ed. Newbury Park: Sage Publications; 1999.

27. Crabtree BF, Miller WL, Howard J, Rubenstein E, Tsui J, Hudson SV, et al. Primary care Clinicians' perspectives of their role in cancer survivorship care: implications for professional identity. Ann Fam Med. 2019. https://doi.org/ 10.1007/s00520-019-04855-5.

28. Parry C, Kent EE, Forsythe LP, Alfano CM, Rowland JH. Can't see the forest for the care plan: a call to revisit the context of care planning. J Clin Oncol. 2013;31(21):2651-3.

29. Gross AH, Leib RK, Tonachel A, Tonachel R, Bowers DM, Burnard RA, et al. Teamwork and electronic health record implementation: a case study of preserving effective communication and mutual Trust in a Changing Environment. J Oncol Pract. 2016;12(11):1075-83.

30. Vogel AL, Hall KL. Creating the conditions for implementing team principles in cancer care. J Oncol Pract. 2016;12(11):964-9.

31. Jain AK, Fennell ML, Chagpar AB, Connolly HK, Nembhard IM. Moving toward improved teamwork in cancer care: the role of psychological safety in team communication. J Oncol Pract. 2016;12(11):1000-11.

32. Lanham HJ, Palmer RF, Leykum LK, McDaniel RR Jr, Nutting PA, Stange KC, et al. Trust and reflection in primary care practice redesign. Health Serv Res. 2016:51(4):1489-514
33. Jordan ME, Lanham HJ, Crabtree BF, Nutting PA, Miller WL, Stange KC, et al. The role of conversation in health care interventions: enabling sensemaking and learning. Implement Sci. 2009;4:15.

34. Paul DL, McDaniel RR Jr. Facilitating telemedicine project sustainability in medically underserved areas: a healthcare provider participant perspective. BMC Health Serv Res. 2016;16:148.

35. Paul DL, McDaniel RR Jr. Influences on teleconsultation project utilization rates: the role of dominant logic. BMC Med Inform Decis Mak. 2016;16(1):155.

36. Desch CE, Benson AB 3rd, Smith TJ, Flynn PJ, Krause C, Loprinzi CL, et al. Recommended colorectal cancer surveillance guidelines by the American Society of Clinical Oncology. J Clin Oncol. 1999;17(4):1312.

37. El-Shami K, Oeffinger KC, Erb NL, Willis A, Bretsch JK, Pratt-Chapman ML, et al. American Cancer Society colorectal cancer survivorship care guidelines. CA Cancer J Clin. 2015;65(6):428-55.

38. Ligibel JA, Denlinger CS. New NCCN guidelines for survivorship care. J Natl Compr Canc Netw. 2013;11(5 Suppl):640-4.

39. Mohler JL. The 2010 NCCN clinical practice guidelines in oncology on prostate cancer. J Natl Compr Canc Netw. 2010;8(2):145.

40. Nekhlyudov L, O'Malley DM, Hudson SV. Integrating primary care providers in the care of cancer survivors: gaps in evidence and future opportunities. Lancet Oncol. 2017;18(1):e30-e8.

41. Oeffinger KC, Argenbright KE, Levitt GA, McCabe MS, Anderson PR, Berry E, et al. Models of cancer survivorship health care: moving forward. In American Society of Clinical Oncology educational book American Society of Clinical Oncology Meeting; 2014. p. 205-13.

42. O'Malley D, Hudson SV, Nekhlyudov L, Howard J, Rubinstein E, Lee HS, et al. Learning the landscape: implementation challenges of primary care innovators around cancer survivorship care. J Cancer Surviv. 2017. 11(1):13-23.

43. Tremblay D, Prady C, Bilodeau K, Touati N, Chouinard MC, Fortin M, et al. Optimizing clinical and organizational practice in cancer survivor transitions between specialized oncology and primary care teams: a realist evaluation of multiple case studies. BMC Health Serv Res. 2017;17(1):834

44. Rhee SO, Luke RD, Culverwell MB. Influence of client/colleague dependence on physician performance in patient care. Med Care. 1980;18(8):829-41.

45. Enomoto LM, Fenstermaker J, Desnoyers RJ, Pasche BC, Blackstock AW Jr, Howerton RM, et al. Oncology navigation decreases time to treatment in patients with pancreatic malignancy. Ann Surg Oncol. 2019;26(5):1512-8.

46. Allemang B, Allan K, Johnson C, Cheong M, Cheung P, Odame I, et al. Impact of a transition program with navigator on loss to follow-up, medication adherence, and appointment attendance in hemoglobinopathies. Pediatr Blood Cancer. 2019;66(8):e27781.

47. Winget M, Holdsworth L, Wang S, Veruttipong D, Zionts D, Rosenthal EL, Asch SM. Effectiveness of a lay navigation program in an academic cancer center. J Oncol Pract. 2019;JOP1900337. https://doi.org/10.1200/JOP.19. 00337. [Epub ahead of print] PubMed PMID: 31647691

48. Mertz BG, Dunn-Henriksen AK, Kroman N, Johansen C, Andersen KG, Andersson $\mathrm{M}$, et al. The effects of individually tailored nurse navigation for patients with newly diagnosed breast cancer: a randomized pilot study. Acta Oncol. 2017:56(12):1682-9.

49. Soukup T, Lamb BW, Arora S, Darzi A, Sevdalis N, Green JS. Successful strategies in implementing a multidisciplinary team working in the care of patients with cancer: an overview and synthesis of the available literature. J Multidiscip Healthc. 2018;11:49-61.

50. Henry E, Silva A, Tarlov E, Czerlanis C, Bernard M, Chauhan C, et al. Delivering coordinated cancer care by building Transactive memory in a team of teams. J Oncol Pract. 2016;12(11):992-9.

51. Weaver SJ, Che XX, Petersen LA, Hysong SJ. Unpacking care coordination through a multiteam system lens: a conceptual framework and systematic review. Med Care. 2018;56(3):247-59.

52. Taplin SH, Weaver S, Chollette V, Marks LB, Jacobs A, Schiff G, et al. Teams and teamwork during a cancer diagnosis: interdependency within and between teams. J Oncol Pract. 2015;11(3):231-8.

53. Pillay B, Wootten AC, Crowe H, Corcoran N, Tran B, Bowden P, et al. The impact of multidisciplinary team meetings on patient assessment, management and outcomes in oncology settings: a systematic review of the literature. Cancer Treat Rev. 2016;42:56-72.

\section{Publisher's Note}

Springer Nature remains neutral with regard to jurisdictional claims in published maps and institutional affiliations. 